with the complexity of most insect genitalia this has resulted in an unnecessary proliferation of names; the most valuable service this work may well achieve is to discourage further coining of terms, and, even better, to reduce the present number. The book is essential to all working taxonomists.

A. Brindle

\section{BABOON ANATOMY}

\section{Primates}

Comparative Anatomy and Taxonomy. Vol. 8: Cynopithecinae. By W. C. Osman Hill. Pp. xix $+680+36$ plates. (Edinburgh University: Edinburgh, April 1970.) $340 s$.

I HAVE had the pleasurable task of reviewing the previous volumes in this formidable series and was therefore alarmed to find the number 8 embossed on the latest volume. Whatever happened to volume seven? The first few lines of the preface explains all: volume seven which deals with the macaques and mangabeys is scheduled for 1971 ; volume eight, bearing the somewhat unfamiliar subtitle "Cynopithecinae" is, for reasons of expediency, out of line. This seems a good decision, bearing in mind the present great interest in the African ground-dwelling Cercopithecinae. Volume eight embraces the genera Papio, Mandrillus and Theropithecus and their extinct ancestors.

We have become so conditioned to the invariability of Dr Osman Hill's scholarship that, with each new volume, it is necessary to remind ourselves of the immense knowledge that has gone into its preparation. Once again, volume eight is an impeccably accurate accumulation of the facts of morphology and taxonomy, but one might wish that behaviour was equally well represented. Possibly this is akin to wishing that Darwin had possessed Mendel's and De Vries' knowledge of the hereditary units. Each generation of scientists contributes to the sum total of knowledge in terms of his own particular exper. tise. Osman Hill is one of the last of a long line of distinguished primate morphologists and his like, as the saying is, may not be seen again.

Sometimes progress in science is more of a threat than a promise. While scientific progress has its undeniable advantages for mankind, it also has a most depressing effect on the tried and true methods of the basic sciences. If it were true that what is new is necessarily good and what is old-hat is (to use a phrase popular among scientific administrators) unfundable, then the scientists would have no complaint, but is it true ? When the electron microscope was introduced, a research project with the light microscope became a non-event, so much so that no ambitious graduate student would willingly opt for the latter if he could possibly climb on the bandwagon of the former. How much information is being missed at cellular level while the eyes of the scientific world are scanning the sub-molecular structure of the cell membrane and its processes? It would be serious indeed if research in primate morphology and the functional interpretation of its discoveries were shunted into the "unfundable" category by the preferentials of new, and as yet unproven, methodologies.

Hill's latest volume will inevitably reach a larger audience than his previous volumes because it deals prineipally with the baboons which enjoy (if that is the word) a high degree of popularity in the medical research field. For this reason it is perhaps unfortunate that Hill's classification is not wholly in line with recent trends in primate systematics, which is to synonymize the species of Papio. It is now recognized that Papio is a single polytypic species with morphologically different sub. species interbreeding wherever they meet. Modern taxonomic thought is divided between retaining two species-P. hamadryas and $P$. cynocephalus-or treating them as conspecific; in which case the specific name would have to be $P$. hamadryas under the Priority Rule. Common sense, for the time being, is in the ascendancy and confusion among the ranks of non-taxonomists is postponed by admitting two species - the sacred baboon ( $P$. hamadryas) and the common baboon ( $P$. cynocephalus). Recent classifications also favour the inclusion of the drills and mandrills in the genus Papio, on grounds that are almost wholly pragmatic, and, in my opinion, biologically. invalid. Fortunately, the informational content of volume eight of Primates is in no way affected by these. nomenclatorial niceties.

The book is profusely illustrated with line drawings and black and white plates. It would be nice to see a few more colour plates; the Devil (or in this case the popular monthly glossies) always seems to have the best tunes. What a pity it is that colour is not as readily available to. scientists, who often require it to prove their point, as it is to purveyors of sex magazines whose point is already proved.

Anybody who possesses the first six volumes of this. series will need no urging to add volume eight to their collection. But for those who have not yet invested in Primates and have a special interest in the African. Cercopithecinae, this new volume will provide a permanent. accurate, up to date source of historical, morphological and physiological information collected by the acknowledged expert in the field of primate morphology.

JOHN NAPIER

\section{GUIDE TO BRITISH LICHENS}

\section{Introduction to British Lichens}

By U. K. Duncan, assisted by P. W. James. Pp. Ixxiv+ 292 + 128. (Buncle: Arbroath, 1970.) 708 .

THE principal object of this book is to assist students and beginners to identify lichens. It does not attempt to be a definitive lichen flora of Britain, and, indeed, it only includes 65 per cent of the species recorded for this country (the other 35 per cent being lichens which the beginner is very unlikely to encounter).

There is no doubt that the book will succeed admirably in its object. It will be extremely useful in lichen identification because the keys are particularly good and are easier to follow than in any other relevant lichen flora; there are adequate descriptions of each species. Unfamiliar terms are explained both in a glossary and in a detailed account of fichen structure in which technical words are put into bold type. There are also lists of species found in different habitats--which, again, will be of great assistance.

The chief defect is the illustrations, consisting of 128 pages of line drawings (unfortunately called plates) which are often tiny, many occupying less than balf the space available to them on the page. If all but a few of the illustrations had not been published, the usefulness of the book would not have suffered, and its price would have been brought more comfortably down into the range acceptable to students. Another irritating feature is that in the excellent key to genera, there is no indication of the page on which the description of a genus occurs. Unless the reader has an accurate and very detailed grasp of lichen classification, he will have to continually turn to the index to locate the relevant page.

Perhaps the basic problem is that the book is published by a firm which seems not to have much experience in publishing this kind of scientific book. This is a great pity because the book is essentially very useful. Miss Duncan has a remarkably good and critical knowledge of lichens, and, as those who attend British Lichen Society excursions will testify, she is outstandingly good at helping beginners. All students of British lichens should have this book.
D. C. SMITH 